\title{
Geçmişten Günümüze Türkçe Öğretim Programlarının Konuşma Becerisi Bakımından Değerlendirilmesi ${ }^{*}$
}

\author{
An Evaluation of Turkısh Curriculum In Terms of Speakıng Skılls \\ From Past To The Present
}

DOI $=\underline{\text { http: } / / d x \cdot \text { doi.org/10.17556/jef.10313 }}$

\author{
Okay DEMIR ${ }^{* *}$
}

\section{Özet}

$\mathrm{Bu}$ çalışmanın amacı, konuşma becerisine, Cumhuriyetin ilanından günümüze ilköğretim birinci kademede yürütülen Türkçe derslerine yönelik hazırlanan öğretim programlarında ne ölçüde yer verildiğini tespit etmektir. Nitel çalışma yöntemi kullanılmıştır. Çalışmada yürürlüğe konan birinci kademe Türkçe öğretim programlarında konuşma becerisine ne oranda yer verildiği incelenmiştir. Değerlendirmede, programın ilk yıllarında konuşma becerisine doğrudan yer verilmeyip bu becerinin varlığının diğer beceri alanlarının satır aralarından anlaşıldığı ve bu beceriye diğer beceri alanlarına göre kısmen önem verildiği, 1968 programından 2005 programına değin bu beceriye ayrı bir başlık altında değinilip önemsendiği sonuçlarına ulaşılmıştır.

Anahtar Sözcükler: Türkçe eğitimi, konuşma becerisi, öğretim programı.

\section{Abstract}

The purpose of this study, the ability to speak, since the declaration of the Republic, Turkish lessons prepared for primary school level education programs carried out to determine to what extent was covered. Qualitative study method was used. In this study, the promulgation of the first stage is given in the Turkish Curriculum were examined to what extent the ability to speaking. In the evaluation, the ability to speaking directly involved in the early years of the program in other skill areas between the lines verilmeyip understood and partly based on other skill areas of importance was attached, until the 1968 Turkish Curriculum 2005 Turkish Curriculum mentioned and heeded these skills are obtained under a separate heading.

Keywords: Turkish education, speaking skills, curriculum. 


\section{Giriş}

Anlatım tekniklerinin amacı, bireylerin gördüklerini duyduklarını, yaşadıklarını, zihinde canlandırdıklarını, okuduklarını ve düşündüklerini söz ve yazı ile doğru, amaca uygun ve güzel bir biçimde anlatma yeteneği kazandırmaktır.

Eğitim süreci içerisinde yer alan ana dili eğitimi, bireyin hem kişisel hem de toplumsal açıdan yetişmesi bakımından özel bir öneme sahiptir. Ana dili eğitiminin verildiği Türkçe derslerinin sistemli bir şekilde yürütülebilmesi için planlanmış programlara ihtiyaç duyulur. Türkçe dersi öğretim programıla dinlediklerini, izlediklerini ve okuduklarını anlayan; duygu, düşünce ve hayallerini anlatan; eleştirel ve yaratıcı düşünen, sorumluluk üstlenen, girişimci, çevresiyle uyumlu, olay, durum ve bilgileri kendi birikimlerinden hareketle araştırma, sorgulama, eleştirme ve yorumlamayı alışkanlık hâline getiren, estetik zevk kazanmış ve millî değerlere duyarlı bireyler yetiştirilmesi amaçlanmaktadır (MEB, 2006). İfade edilen amaçlara bakıldığında öğrencinin dil becerilerinin (dinleme, konuşma, okuma, yazma) geliştirilmesi gerekliliği ortaya çıkmaktadır. Türkçe dersinde başarıya ulaşılmak isteniyorsa her bir becerinin aynı ölçüde geliştirilmesine özen gösterilmelidir.

$\mathrm{Bu}$ becerilerden konumuzla ilgili olan konuşma becerisi, insanlar arasında iletişim sağlayan en yaygın ve önemli beceridir. Ünalan (2001)'a göre, çocuklar konuşmaktan çekinebilecekleri için onlara ilk yıllarda fazla müdahale edilmemelidir; aksi halde çocuk kendi kabuğuna çekilebilir, sınıf etkinliklerinden uzak durabilir. Konuşma eğitimin de temel aracı olup çocuklar okula gelmeden önce konuşmayı aşağı yukarı öğrenmiş olurlar. Ancak bu konuşmaların kısmen yetersiz olduğu söylenebilir. Temizyürek (2007)'e göre, okullarda konuşma becerisini geliştirmeye yönelik çeşitli çalışmalar yapılabilir. Örneğin, konuşma çalışmalarına çocukların yakın çevrelerinden başlanmalı, giderek daha uzak çevrelere ait konular üzerinde konuşmalar yapılmalıdır. Bu sırada öğretmen, çocukları sabırla ve hoşgörüyle dinlemelidir. Çünkü öğrencilerin iyi birer konuşma yapabilmeleri için, söylediklerine değer verildiğini bilmeleri ve hissetmeleri gerekmektedir. Öğrencinin konuşması için mutlaka bir sebep bulunmalı ve buna bağlı olarak, öğrenci konuşurken öğretmen de onu anlayışla 
dinlemelidir. Kurudayığlu (2003), sınıf ortamında konuşma becerisinin geliştirilmesine yönelik uygulanabilecek etkinlikleri şu şekilde sıralamıştır:

- Öğrencilere konuşma esnasında uymaları gereken kurallar olduğu sürekli hissettirilmelidir. Konuşmak için öğrencilere ve öğretmene yönelen öğrenci, arkadaşlarına (gerekiyorsa) kendini tanıtmalı, amacından sapmadan, giriş, gelişme ve sonuç planlarını göz önünde tutarak, bilgilerini, gördüklerini, düşüncelerini açık ve sade bir şekilde anlatabilmelidir.

- Öğrencilerin konuşma becerilerini geliştirmenin bir yolu da onlara seviyelerine uygun sorular sormaktır. Öğrenciler gerek okuma metni ile gerekse, dil bilgisi veya diğer konularla ilgili sorular sorarak yakından takip edilmeli, hataları anında düzeltilmelidir.

- Anlatma çalışmaları yaparak konuşma becerileri geliştirilebilir. Anlatmaya her insanda hazır olan anıdan başlamak çok yararlıdır. Öğrenci kendine göre özgürce seçeceği bir konuyu, bir anısını sınıfta arkadaşlarına anlatacaktır. Bu çalışma için öğretmen ilk önce örnek olarak birkaç anısını sınıfta anlatmalıdır. Anı anlatmak öğrencilerin yaşadıkları, hissettikleri doğrudan merkezi o olan yaşantıların anlatımı olduğu için, öğrenciler açısından yapılabilecek en kolay ve faydalı konuşma eğitimidir.

- Konuşma eğitimi için bir diğer anlatma çalışması da gezi anlatımıdır. Öğrencinin gezi ve gözlem yoluyla elde ettiği bilgi, izlenim, edindiği fikir, hissettiği duygu anlattırılır. Bu çalışma da tıpk1 anı anlatımında olduğu gibi öğrencinin doğrudan kendi gözlemlerine dayandığı için konuşma eğitimi açısından önemlidir. Öğrenci yaptığı bir geziyi, özellikle gözeleri arasından seçeceği bir gezisini sınıfta arkadaşlarına anlatabilir.

- Yine anlatma çalışmaları arasında yapılabilecek diğer bir etkinlik de bir masal, öykü anlatımıdır. Bu anlatımda öğrenci anlatacağı masal ya da hikâyeyi kendisi seçmeli, daha sonra s1nıfta arkadaşlarına anlatmalıdır.

- Günlük gazete veya değişik dergilerden okunan bir yazının s1nıfta anlatılması da konuşma eğitimi etkinlikleri olarak yapılabilir. Öğrenci hem okumaya yönlendirilir hem de okuduklarını 
anlatma firsatı verilerek bu konuda cesaretlendirilir. Öğrenci eleştirel okuma yönünde de geliştirilir.

- Okunan bir hikâyenin, masalın veya romanın anlatılması da etkili bir çalışmadır. Öğrencilere özetlemek teriminden bahsedilmeden okuduğundan ne anladığı anlattırılmalıdır.

- Metinlerde yer alan olayların sonuçlarını tahmin etme çalışmaları da konuşma eğitiminde kullanılabilecek etkinliklerdendir. Örneğin şöyle bir çalışma yapılabilir; metinde, hikâyede, görüntüde gösterilen durumun sonuçlarının öğrenciler tarafından siralanması istenebilir. Bu durumdan sonra da metindeki durumdan az sonra ya da gelecekte olabilecekler tahmin ettirilebilir.

- Konuşmanın zihinsel süreçlerinin geliştirilmesine yönelik olarak öğrencilere sınıflandırma, ilgilendirme, gruplandırma çalışmaları yapılabilir.

- Hayal kurma ve bu hayalleri sınıfta anlatma çalışmaları da konuşma eğitiminde yapılacak etkinliklerdendir. $\mathrm{Bu}$ çalışma da beynin zihinsel sürecini hedef almaktadır.

Tüm bu gereklilikler bir yana, Heath (1983) de, ilköğretim okulları düzeyinde sınıf içi konuşmaların değeri üzerine yaptığı araştırmada konuşmanın, dil öğretim sürecinin önemli bir unsuru olduğunu ve bütün konu alanlarında başarı açısından gerekli olduğunu ortaya koymuştur. Sınıf ortamında öğrencinin sessizce oturmasının öğretimi olumsuz yönde etkilediği görülmüştür.

Bir ülkenin eğitiminin en önemli yapıtaşlarından birisi de kuşkusuz ders programlarıdır. Ders programları ne kadar yetkinse ülkede verilen eğitimin kalitesi de o oranda yüksektir. Türkçe ders programı özelinde düşündüğümüzde programın, yetkinliği sayesinde ülke vatandaşlarının birbiriyle anlaşma, doğru ve sağlıklı iletişim kurma, gönül birlikteliğinin ve bütünlüğünün sağlanması ve sair sebeplerden önemi ortadadır.

Yukarıda da açıklandığı üzere geçmişten günümüze Türkçe öğretim programlarında yer alan "Konuşma" becerilerini inceleme gereksinimi bu araştırmanın problemini oluşturmaktadır. 


\section{Çalışmanın Amacı}

$\mathrm{Bu}$ çalışmanın amacı, konuşma becerisine, Cumhuriyetin ilanından bugüne ilköğretim birinci kademede yürütülen Türkçe derslerine yönelik hazırlanan öğretim programlarında ne ölçüde yer verildiğini tespit etmektedir.

\section{Sinırlılıklar}

Çalışma, Cumhuriyetin ilanından günümüze uygulamaya konulan birinci kademe Türkçe öğretim programlarında yer alan konuşma becerisine ilişkin ifadeler ile sınırlıdır.

\section{Yöntem}

$\mathrm{Bu}$ çalışmada nitel araştırma yöntemlerinden doküman incelemesi kullanılmıştır. Doküman incelemesi, araştırılması hedeflenen olgu veya olgular hakkında bilgi içeren yazılı materyallerin analizini kapsar. Eğitim ile ilgili bir araştırmada ders kitapları, program yönergeleri vb. veri kaynağı olarak kullanılabilir (Yıldırım ve Şimşek, 2008). Çalışmada yürürlüğe konan birinci kademe Türkçe öğretim programlarında konuşma becerisine ne oranda yer verildiği bu bağlamda incelenmiştir.

\section{Bulgular ve Yorum}

Aşağıda Cumhuriyet'in kuruluşundan günümüze, ilköğretim birinci kademe Türkçe öğretim programlarında Konuşma becerisine ilişkin bulgulara yer verilmektedir.

\section{İlköğretim Birinci Kademe Programlarında Konuşma Becerisi}

İlköğretim birinci kademede bugüne kadar toplam yedi programın uygulamaya konulduğu tespit edilmiştir.

1924 Illk Mekteplerin Müfredat Programları'nda konuşma becerisini geliştirmeye yönelik ayrı bir ders yer almamakla birlikte, bu beceriye yönelik uygulama ve açıklamalar diğer beceri alanlarının 
satır aralarından çıkarılmaktadır. Özellikle Kıraat ve İnşad (yüksek sesli ve vurgulu okuma) derslerinden hareketle öğrencilerin konuşma becerilerinin de geliştirilmeye çalışıldığ 1 söylenebilir.

1926 Illk Mekteplerin Müfredat Programı ile 1930 Ilk Mektep Türkçe Müfredat Programı'nda konuşma becerisiyle ilgili bilgilere müfredatın amaçlar bölümünde ve şifahi temrinler (sözlü egzersizler) başlığı altında değinildiği görülmektedir. Dersin hedefleri incelendiğinde, "Talebeye, düşündüğünü, duyduğunu ve bildiğini diğer kimselere şifahen veya tahriren doğru ve güzel anlatmak kabiliyetini iktisap ettirmek", "Lisan vasıtasıyla çocuklarda iyi ve güzel hisleri tenmiye ederek kendilerinde sinn ü seviyelerine göre bir zevk-i edebi uyandırmak", "Mahalli şiveleri isti'mâl eden talebenin ifadelerini tedricen tahsis ederek onları milli şiveye (İstanbul şivesine) istînâs ettirmek" ifadelerinin yer aldığı görülmektedir. Programda yer alan beş hedeften üçünün doğrudan konuşma becerisi ile ilişkisi olması bu beceriye verilen önemi göstermektedir. Şifahi temrinler (sözlü egzersizler) dersinin içeriği ise; Çocuğun çevresinde cereyan eden olaylar ve eşyalar, çocuğun kendi başına yaşadığı deneyimler, Masallar, kıraat kitabından okutulan bir parçanın mealinin serbestçe anlattırılması, mahalli şivede konuşan çocukları İstanbul Türkçesi konuşmaya alıştırmak, öğretmenlerin konuşma bozukluğu olan (kekeme, peltek) çocukları bilhassa konuşturmaya gayret etmesi, ilk senenin ifade dersinde öncelikle küçük cümlelerden başlanılması, şifahi ifade derslerinde ilerleme kaydedilince el işi ve musiki dersleri ön plana alınması faaliyetleridir. Sözlü egzersizlerde yer alan içeriğe bakıldığında bilhassa çocuğun yakın çevresinin tercih edildiği, çocukların seviyelerinin gözetildiği, anlatımda birlik sağlama ihtiyacının olduğu görülmektedir.

1936 İlkokul Türkçe Programı'nda, hedefler kısmında “Talebeye; bildiğini, düşündüğünü ve duyduğunu sözle ve yazı ile iyi ve doğru olarak anlatmak iktidarını kazandırmak" ve "Dilimizin tabi olduğu esaslı kaideleri sezdirip sınırlandırmak sureti ile Türk dilini kullanışta güven kazandırmak" ifadeleriyle konuşma becerisine yer verildiği görülmektedir. Bu ifadelerde geçen Türk dilini kullanmak ve sözle anlatmak ifadelerinde konuşma becerisinin kastedildiği anlaşılmaktadır. Ayrıca öğrencilerin kendilerini ifade ederlerken öğretmenlerin hangi noktalara dikkat etmeleri gerektiği de sıralanmıştır. 
1948 Illkokul Türkçe Programı'nda, hedef yerine amaç ifadesinin yer aldığını görüyoruz. Konuşma becerisi ile de ilgili dolaylı olarak iki amaç bulunmaktadır. Bunlar : "Öğrencilere gördüklerini, duyduklarını, bildiklerini, incelediklerini, düşünüp tasarladıklarını sözle ve yazı ile iyi ve doğru olarak anlatma kudretini kazandırmak” ve "Dilimizin bağlı olduğu ana kuralları sezdirip onlara Türk dilini kullanmada güven kazandırmak" ifadeleridir. Burada sözlü anlatım ve Türk dilinin kullanımı ifadeleri konuşma becerisini çağrıştırmaktadır. Programda söz ve yazı ile ifade bir arada verilmekte ve söz ile ifade başlığında özetle öğretmenin sınıfında doğru ve düzgün bir şekilde konuşulmasını sağlaması, sözle ifade için başlı başına bir ders ayrılmadığı, dersler ve ders dışı çalışmalar için firsatlar sağlanması gerektiği, öğretmenin çocukların cesaretini kırmaması ve onların öz dilleriyle konuşmalarına imkân vermesi gerektiği, sınıfça ve kümeler içinde konuşma yöntemlerine başvurulabileceği, gezintiler, ziyaretler ve müsamereler gibi sınıf dışı faaliyetler sırasında da öğrencilerin konuşmaları için zemin hazırlanacağı, öğretmenin, çocuklara kendine sıra gelmeden söze karışmamak, arkadaşlarının fikirlerine saygılı olmak, tenkitler sırasında kırıcı olmamak vs. gerektiğini çocuklara öğretmesinin gerekliliği, söz söyleme çeşitlerinden hangisi olursa olsun amacın çocukların yaratıcılık yeteneğinin geliştirilmesi olduğu konularının üzerinde durulduğu görülmektedir. Sınıf seviyelerine göre konuşma becerisine ilişkin davranışlar da ilk defa belirtilmektedir.

1968 Illkokul Türkçe Programı'nda, konuşma becerisiyle ilgili olduğu düşünülen iki amaç cümlesi bulunmaktadır. Bunlar: "Gördüklerini, duyduklarını, bildiklerini, incelediklerini, öğrendiklerini, düşünüp tasarladıklarını sözle veya yazı ile doğru, amaca uygun ve etkili olarak anlatma gücünü kazanırlar" ve "Gözlem ve araştırma yolu ile edindikleri izlenim ve bilgileri söz ve yazı ile anlaşılır ve ilgi uyandırıcı bir şekilde anlatabilme becerilerini kazanırlar" ifadelerdir. Burada sözlü ve yazılı anlatım birlikte yer almakta, sözlü anlatımla da konuşma becerisi kastedilmektedir. Programda sözlü anlatım başlığı altında ayrı bir bölüm yer almakta ve burada öğretmenlerin bu beceriyi desteklerken dikkat etmeleri gereken hususlara yer verilmekte ve öğrencilerde konuşma becerisini geliştirmede faydalanılacak etkinlikler yer almaktadır. Ayrıca sınıf seviyelerine göre konuşma becerisine ilişkin davranışlar da belirtilmektedir. 
1981 Illköğretim Okulları Türkçe Eğitim Programı'nın amaçlar bölümünde konuşma becerisiyle ilgili “Onlara, görüp izlediklerini, dinlediklerini, okuduklarını, incelediklerini ve düşündüklerini, tasarladıklarını söz ya da yazı ile doğru ve amaca uygun olarak anlatma beceri ve alışkanlığını kazandırmak”, “Öğrencilere Türk dilini sevdirmek, kurallarını sezdirmek; onları Türkçe'yi gelişim süreci içinde bilinçle, özenle ve güvenle kullanmaya yöneltmek" amaçlarına yer verilmektedir. Anlatım başlığı altında konuşma becerisi ile ilgili özel amaçlara yer verilmekte ve 1948 ve 1968 programlarında olduğu gibi bu beceriye ilişkin sınıf seviyelerine göre davranışlar belirtilmektedir. Sözlü anlatım ve konuşma çeşitleri faaliyetleri 1968 programından aynen alınmıştır. İlk defa bu programda ayrı bir başlık halinde yer bulan ölçme değerlendirme bölümünde ise, anlattırma başlığı altında bu beceriye yönelik ölçme faaliyetleri yer almaktadır.

2005 Illkögretim Okulları Türkçe Dersi Öğretim Programı'nda, konuşma becerisine yönelik ilk bulguya giriş bölümünde yer alan iki amaç ifadesiyle rastlanılmaktadır. Bunlar: "Öğrencilerin duygu, düşünce ve hayallerini sözlü ve yazılı olarak etkili ve anlaşılır biçimde ifade etmelerini sağlamak”, “Öğrencilerin Türkçeyi konuşma ve yazma kurallarına uygun olarak bilinçli doğru ve özenli kullanmalarını sağlamak" ifadeleridir. Yine burada konuşma ve yazma becerilerinin birlikte yer aldığını görüyoruz. Temel beceriler başlığı altında da konuşma becerisi yer almakta, buna göre temel beceriler öğrencilerin dil becerilerindeki gelişimleriyle bağlantılı, yatay olarak bir yılın sonunda, dikey olarak da 8.sınıfin sonunda kazanacakları ve hayat boyu kullanacakları temel beceriler olarak tanımlanmaktadır. Programın giriş bölümünde konuşmayla ilgili olan son başlık "temel dil becerileri" olup burada konuşma becerisinin önemine değinilmekte ve bu beceriyle ilgili etkinlik örneklerine yer verilmektedir. Konuşma becerisinin değerlendirme aşamasında, öncelikle öğrencilerin kendilerini veya birbirlerini değerlendirmeleri, hedeflenen kazanımların daha da kalıcı olmasını sağlayarak öğrencilerin konuşmayla ilgili yeteneklerini geliştirilecektir. Programda, konuşma becerisi ile ilgili olarak konuşma kurallarını uygulama, sesini ve beden dilini etkili kullanma, hazırlıklı konuşmalar yapma, kendi konuşmasını değerlendirme, kendini sözlü olarak ifade etme alışkanlığı kazanma amaçlarına yönelik kazanımlara yer verilmiştir. Ayrıca konuşma becerisini geliştirmek amaciyla uygulanabilecek yöntemlere de yer verilmiştir. Bunlar: İkna 
etme, eleştirel konuşma, katılımlı konuşma, tartışma, empati kurma, güdümlü konuşma, kelime ve kavram havuzundan seçerek konuşma, serbest konuşma, yaratıcı konuşma ve hafızada tutma tekniğidir.

\section{Sonuç ve Tartişma}

Eğitimin ve iletişim becerilerinin temeli olan konuşma becerisi sağlıklı anlaşmanın ve toplumdaki çatışmaların önlenmesinin ön koşuludur. Bu sebeple bireyin ilk çevresi olan aileden başlayarak okul yaşamı ve sonrası da olmak üzere konuşma becerisinin önemi ortadadır. $\mathrm{Bu}$ becerinin sistemli bir şekilde işlendiği ve planlandığı yer okullardır. Konuşma becerisinin yer aldığı Türkçe dersi öğretim programları Cumhuriyetin ilanından günümüze kronolojik süreç içerisinde değerlendirilmiştir.

Değerlendirmeden çıkan sonuçlara göre, programın ilk yıllarında konuşma becerisine doğrudan yer verilmeyip diğer beceri alanlarının satır aralarından anlaşıldığı ve diğer beceri alanlarına göre kısmen önem verildiği, 1968 programından itibaren 2005 programına değin bu beceriye ayrı bir başlık altında değinilip önemsendiği sonuçlarına ulaşılmıştır.

Son yıllarda Türkçe dersi kapsamında öğrencilerde konuşma becerilerinin durumuna ilişkin birçok çalışma yapıldığı göze çarpmaktadır. Bayraktar ve Doğan (2014), beşinci sınıf öğrencilerinin Türkçe dersi konuşma becerilerini değerlendirdikleri çalışmalarında, öğrencilerin "Konuşma Becerilerini Değerlendirme Ölçeği”"ne göre, "Kendini Sözlü Olarak İfade Etme" ve "Konuşma Kurallarını Uygulama" alt boyutundan aldıkları puanların ortalamasının görece yüksek düzeyde olduğunu; kızların "Konuşma Becerilerini Değerlendirme Ölçeği”nden aldıkları toplam puanların, erkeklerin konuşma becerileri toplam puanlarından daha yüksek çıktığını; Kızların "Konuşma Becerilerini Değerlendirme Ölçeği"nin hem "Kendini Sözlü Olarak İfade Etme", hem de "Konuşma Kurallarını Uygulama" alt boyutundan aldıkları puanların, erkeklerin puanlarından daha yüksek olduğunu bulgulamışlardır. Öte yandan, Er ve Demir (2013), konuşma becerisinin Türkçe öğretmenleri tarafından kullanılabilirliğine ilişkin Türkçe öğretmen adaylarının görüşlerini inceledikleri araştırmalarında, öğrencilerin öğretmenlerin sözcük dağarcıklarının yeterli olmamasından dolayı sıkıntı yaşadıklarını bulgulamışlar, bunun yanında sözcük 
dağarcığı yetersizliğinde yapılan içerik analizi sonucunda kısıtlı sözcük dağarcı̆̆ı, yerel ağı, tekrar kelimeler, yetkin olmama, kitap okumama, kitaptaki sözcükle yetinme, derse hazırlıksız gelme, ders kitabına bağlılık, etkisiz anlatım, düzensiz anlatım, kılavuz kitaba göre anlatım, disiplinsizlik şeklinde olumsuz kodlara ulaşmışlardır. Karakoç Öztürk ve Altuntaş (2012) da, ilköğretim ikinci kademe konuşma eğitimine ilişkin öğretmen görüşlerini inceledikleri araştırmalarında, öğrenci seviyelerinin üzerinde bulunan amaç ve kazanımları, konuşma eğitiminde kullanılan etkinlik, yöntem-teknik, araç-gereç ve ölçme araçları ile karşılaşılan güçlükleri belirlemişlerdir. Temizkan (2009), konuşma becerisine başka bir açıdan yaklaşarak, akran değerlendirmenin konuşma becerisinin geliştirilmesi üzerindeki etkisini incelemiştir. Araştırmanın sonuçlarına göre, hazırlıklı konuşma uygulamas1 yapan öğrencilerin akran değerlendirme puanlarına ilişkin ön test ve son test sonuçları arasında son test lehine anlamlı bir ilişki bulunduğu, akran değerlendirme formunun "dil ve anlatım" ile "sunum" aşamalarına ilişkin ön test ve son test sonuçları arasında son test lehine anlamlı bir ilişki bulunduğu, formun "içerik" aşamasına ilişkin ön test ve son test sonuçları arasında herhangi bir anlamlı ilişki tespit edilemediği bulgulanmıştır.

\section{Kaynaklar}

Bayraktar, H. V. ve Cihangir, D. (2014). Beşinci sınıf öğrencilerinin Türkçe dersi konuşma becerilerinin değerlendirilmesi. İZÜ Sosyal Bilimler Dergisi, 4, 37-50.

Heath, S.B. (1983). Research Currents. A Lot of Talk About Nothing. Language Art, 60, 999-1007.

Er, O. ve Demir, Ö. (2013). Konuşma becerisinin Türkçe öğretmenleri tarafından kullanılabilirliğine ilişkin Türkçe öğretmeni adaylarının görüşlerinin incelenmesi. Turkish Studies, 8(1), 1417-1436.

Karakoç Öztürk, B. ve Altuıntaş, İ. (2012). İlköğretim ikinci kademede konuşma eğitimine yönelik öğretmen görüşleri: nitel bir çalışma. Ĕgitim ve Öğretim Araştırmaları Dergisi, 1(2), 342-356.

Kurudayıoğlu, M. (2003). Konuşma eğitimi ve konuşma becerisini geliştirmeye yönelik etkinlikler. Türklük Bilimi Araștırmaları, 13, 287-309.

MEB (2006). İlköğretim Türkçe Dersi (6, 7, 8. Sinıflar) Öğretim Programı. Ankara: Millî Eğitim Bakanlığı Yayınları.

Maarif Vekaleti (1924). Illk Mekteplerin Müfredat Programları. İstanbul: Matbaa-i Amire. 
Maarif Vekaleti (1926). Illk Mekteplerin Müfredat Programları. İstanbul: Millî Matbaa.

Maarif Vekaleti (1936). Yeni Illkokul Müfredat Programı. İstanbul: Devlet Matbaas1. MEB (1948). İlk Okul Programı. İstanbul: Millî Eğitim Basımevi.

MEB (1968). İlkokul Programı. İstanbul: Millî Eğitim Basımevi.

MEB (1981). İlköğretim Okulları Türkçe Eğitim Programı. İstanbul: Millî Eğitim Basımevi.

MEB (2005). İlköğretim Türkçe Dersi Öğretim Programı. Ankara: Millî Eğitim Basımevi.

Temizyürek, F. (2007). İlköğretim ikinci kademede konuşma becerisinin geliştirilmesi. Ankara Üniversitesi Eğitim Bilimleri Fakültesi Dergisi, (40)2, 113-131.

Temizyürek, F. ve Balcı, A.(2006). Cumhuriyet dönemi ilköğretim okulları Türkçe programları. Ankara: Nobel Yayın Dă̆ıtım.

Ünalan, Ş. (2001). Türkçe ögrretimi. Ankara: Nobel Yayınc1lık.

\section{Purpose}

\section{Extended Summary}

Curriculum is undoubtedly one of the most important building blocks of a country. The more advanced countries, the quality of the education curricula that high. We consider the case of Turkish curriculum program and capability of citizens of the country thanks to an agreement with each other, accurate and reliable communication, peace of mind and ensure the integrity of the association and the importance of other reasons are obvious. As described above in the past to the present Turkish Curriculum "Speaking Skills" is the problem of this study is the need for examination. Purpose, speaking ability, since the proclamation of the Republic, Turkish lessons prepared for primary school level Curriculum conducted in the given extent is determined.

\section{Method}

The study was implemented in the present proclamation of the Republic in the first-grade Turkish Curriculums are limited to statements related to speaking skills. In this study, qualitative research methods used in document analysis. Document analysis aimed to investigate cases or covers analysis of written materials containing information about the cases. In a study on education textbooks, software instructions and so on. can be used as a data source (Yıldırım ve Şimşek, 2008). In this study, the ability to put into effect what percentage of the first grade in the speaking skills given in Turkish Curriculum examined in this context.

\section{Results}

First grade in Primary, a total of seven programs are put into practice so far been identified. 1924 Curriculum is not included in a separate course to improve speaking skills, these skills in other skill areas for the application and com- 
ments between the lines removed. 1926 and 1930 Curriculums, objectives and verbal information about the speaking skill exercises are discussed under. 1936 Curriculum, the students to express themselves and also should pay attention to which points the students to express themselves while they are listed in the teachers. 1948 Curriculum has two objectives are indirectly related to the ability of speaking. Behavior is also related to speech class for the first time according to the level indicated. 1968 Curriculum is located in the verbal and written expression; verbal expression refers to the ability of speaking. The program is located in a separate section under the heading of verbal expression, and here the skill of teachers and students are given support in the matters that must pay attention to the events is utilized to develop speaking skills. In addition, behaviors related to speech, stated that according to class level. 1981 Curriculum, lectures are given in the special purposes related to the ability of speaking under the title of the 1948 and 1968 programs, as well as the level of this skill-based behaviors for the class indicated. 1968 program of activities has been the same types of verbal expression and speech. A separate title for the first time in this program is part of the finds in the assessment, measurement activities for this capability is under lectures. Under the headings of the 2005 Curriculum objectives and basic skills included in this skill are provided. The importance of speaking skills are mentioned in these sections and examples are given in this skillrelated activity. Speaking skill assessment stage, the students' reviews of themselves or each other, ensuring that the target achievement a more permanent speech-related abilities of students will be developed. In the program, the ability of speaking about the application of the rules of speech, voice, and body language effectively, using prepared speeches, making his own speech evaluation, for the purpose of earning gains in the habit of expressing himself verbally given. In addition, the methods can be applied in order to develop speaking skills is also included.

\section{Conclusion}

Education and communication skills, speaking skills are the foundation of a healthy society and in the agreement is a prerequisite for the prevention of conflicts. For this reason, starting from the school life of the individual and the family, even after the surrounding area, including the importance of speaking skill is obvious. This skill was committed in a systematic way and planned in the schools. Turkish Curriculum, including speaking skills proclamation of the Republic were in the process of the present chronological order. According to the results of this evaluation, the ability to talk directly involved in the early years of the program in other skill areas between the lines understood and partly based on other skill areas of importance was attached, from the 2005 program in 1968 until the program mentioned and heeded these skills are obtained under a separate heading. 